\title{
Line-transect data may not produce reliable estimates of interannual sex-ratio and age structure variation in West African savannah ungulates
}

\author{
Emmanuel M. Hema ${ }^{1-3}$, Yaya Ouattara ${ }^{4}$, Maomarco Abdoul Ismael Tou ${ }^{4}$, Giovanni Amori ${ }^{5 *}$, \\ Mamadou Karama ${ }^{4}$ and Luca Luiselli ${ }^{3,6,7}$ \\ ${ }^{1}$ Université Dédougou, UFR/Sciences Appliquées et Technologiques, Dédougou, Burkina Faso; \\ ${ }^{2}$ Laboratoire de Biologie et Ecologie Animales, Université Ouaga 1 Prof Joseph Ki Zerbo, Ouagadougou \\ Burkina Faso; ${ }^{3}$ Institute for Development, Ecology, Conservation and Cooperation, Rome, Italy; \\ ${ }^{4}$ Secrétariat Exécutif, AGEREF/CL, Banfora, Burkina Faso; ${ }^{5}$ Research Institute on Terrestrial \\ Ecosystems, CNR, Rome, Italy; ${ }^{6}$ Department of Applied and Environmental Biology, Rivers State \\ University of Science and Technology, Port Harcourt, Nigeria, ${ }^{7}$ Département de Zoologie, Faculté des \\ Sciences, Université de Lomé, Togo
}

Received for publication: 30 April 2019; Revision received: 8 March 2020; Accepted for publication: 13 March 2020

\begin{abstract}
Adult sex ratios and age structures are important wildlife population parameters, but they have been poorly investigated in ungulate species in West African savannahs. We used line transects to investigate these parameters in 11 ungulates from a protected area in south-western Burkina Faso during the period 2010-2018. We created an empirical model of "detectability" for each species based on its main ecological characteristics (habitat and group size) and body size, and then compared the observed interannual inconsistency in sex ratios and age structures with the a priori detectability score. Six out of 11 species showed low interannual inconsistency in sex ratio and age structure. In $82 \%$ of the study species, however, the predicted detectability score matched the observed score, with two exceptions being Tragelaphus scriptus and Sincerus caffer.
\end{abstract}

Key words: Ungulates; population structure; Comoé-Léraba; line transect; predictive "detectability" model.

\section{Introduction}

Expert-based approaches have been increasingly used in applied ecology studies, with a focus on management actions, especially in sites with difficult logistics and when the target species are poorly known or difficult to survey in the field (e.g., Amici and Battisti 2009; Battisti and Luiselli 2011; Battisti et al. 2014).

Studies on adult sex ratio and age structure (i.e., the proportion of juveniles versus adults) are very important in order to define population parameters of animals (e.g., Caughley 1977), including wild ungulates (e.g., Karanth and Sunquist 1992; Berger and

\footnotetext{
*Corresponding author. E-mail: giovanni.amori@cnr.it

${ }^{\circ}$ Copyright: the Author(s), 2020 | Licensee PAGEPress, Italy
} 
Gompper 1999; Clutton-Brock and Coulson 2002; Festa-Bianchet et al. 2003; De Cesare et al. 2012). These studies are also important to help define management and conservation approaches for ungulates (e.g., Ginsberg and Milner-Gulland 1994; Gaillard et al. 2008). It is therefore not surprising that ecologists have long studied demographic parameters in ungulates in East and Southern Africa, where these mammals are often observed in abundant, easy-to-observe, populations (e.g., Dasmann and Mossman 1962a, 1962b; Bourliere 1965; Spinage 1972; Hillman 1986; Mason 1990; Owen-Smith and Mason 2005). In contrast, Central and West African ungulates have been poorly studied with regard to sex ratio and age structure (Turkalo and Klaus-Hügi 1999), especially because their populations are small sized, heavily fragmented and uneasy to be observed.

One of the most intensely used sampling techniques for determining aspects of population demography of African ungulates is the line-transect survey (e.g., Plumptre 2000; Ogutu et al. 2006; Sutherland 2006; Viquerat et al. 2012). However, although several line-transect studies are available, it is not fully understood whether line-transect sampling can provide reliable data on adult sex ratios and juvenile-to-adult ratios for the various species of ungulates, or whether the species-specific ecological characteristics of the various species may affect the reliability of the collected data, such as through biases in the relative detectability of the various target species.

From 2010 to 2018, we used line transects to study 11 ungulate species in a protected area in south-western Burkina Faso (West Africa). Our aim was to test the viability of using line trasects to estimate the interannual inconsistency of sex ratios and age structures. We created a simple a priori model predicting the "performance" of the line-transect surveys. We used species-specific characteristics of body size, habitat use, and group size to estimate a "detectability" score for each of the 11 ungulate species. A species having a high "detectability" score would likely have the most consistent sex ratios and age structures across years. Thus, we divided the 11 species into three groups based on degree of detectability: high, medium, and low. Then, we compared the predicted model with empirical field data to assess the viability of line-transect surveys for assembling reliable data on sex ratios and age structures of West African savannah ungulates.

\section{Materials and methods}

\section{Study area}

This study was carried out during the dry season (February-May) over an 8-year period (2010-2018) in the Forest Classée et Reserve Partiel de Faune / Comoé-Leraba (FCRPF / $\mathrm{CL}$ ), a 1,245 $\mathrm{km}^{2}$ protected area in south-western Burkina Faso (region of Cascades, province of Comoé, departments of Mangodara and Niangoloko) (Figure 1). The reserve is about 100 $\mathrm{km}$ south of Banfora, capital city of the Cascades region. The southern limit is about $150 \mathrm{~km}$ along the international boundary with Côte d'Ivoire (Thiombiano and Kampmann 2010).

The climate is similar to that of southern Sudan with a rainy season of six months (May to October) and a dry season for the rest of the time (Guinko 1984). The study area is a transition zone between the dry tropical climates of the Sahelian north and the humid ones of southern Guinea. During the dry season, the prevailing winds are Harmattan, and during the rainy season, a humid warm monsoon wind blows from the southwest. Average rainfall ranges 200-950 mm (Thiombiano and Kampmann 2010). The Comoé and the Léraba rivers are the two most important rivers in the area. They are perennial and cross the zone from north to south by the Comoé and from the west to the east by the Leraba. The plains are traversed by important rivers, which cause flooding during the rainy season in some places. 
The vegetation is characterized by semi-deciduous forest galleries and open forests, with the dominant species being Daniellia oliveri, Isoberlinia doka, Pterocarpus erinaceus, Khaya senegalensis, Detarium microcarpum, Burkea africana, and Vitellaria paradoxa (Thiombiano and Kampmann 2010).

\section{Protocol}

We applied a line-transect methodology in this study (see Hema et al. 2017a for details). We systematically placed transects (61 lines) at an average equidistance of $1.7 \mathrm{~km}$ and with a north-south and east-west orientation depending on the major drainage line of the major rivers in the census zone. Starting time was 6 a.m., 13 teams of three people each walked simultaneously along transects in straight lines, using GPS Garmin 64s. Every team consisted of an experienced warden (team leader) and two observers (one from the riverine villages and one field tracker). The same persons carried out the transects year-by-year.

Teams used binoculars to record data on the observed species, abundance, sex, age, and group size. Adult individuals that could not be sexed were also noted and recorded as undetermined (these individuals were not considered in the present paper). Depending on the species, sex was determined based on multiple criteria including general body size, shape of face or head, presence or absence of horns, observation of genital organs, and behaviour (i.e., association of calves and individual females, or association with other adults (solitary bulls in some species, groups of females, or groups of males). Details of sex determination criteria for each species are given in online supplementary materials (Table S1).

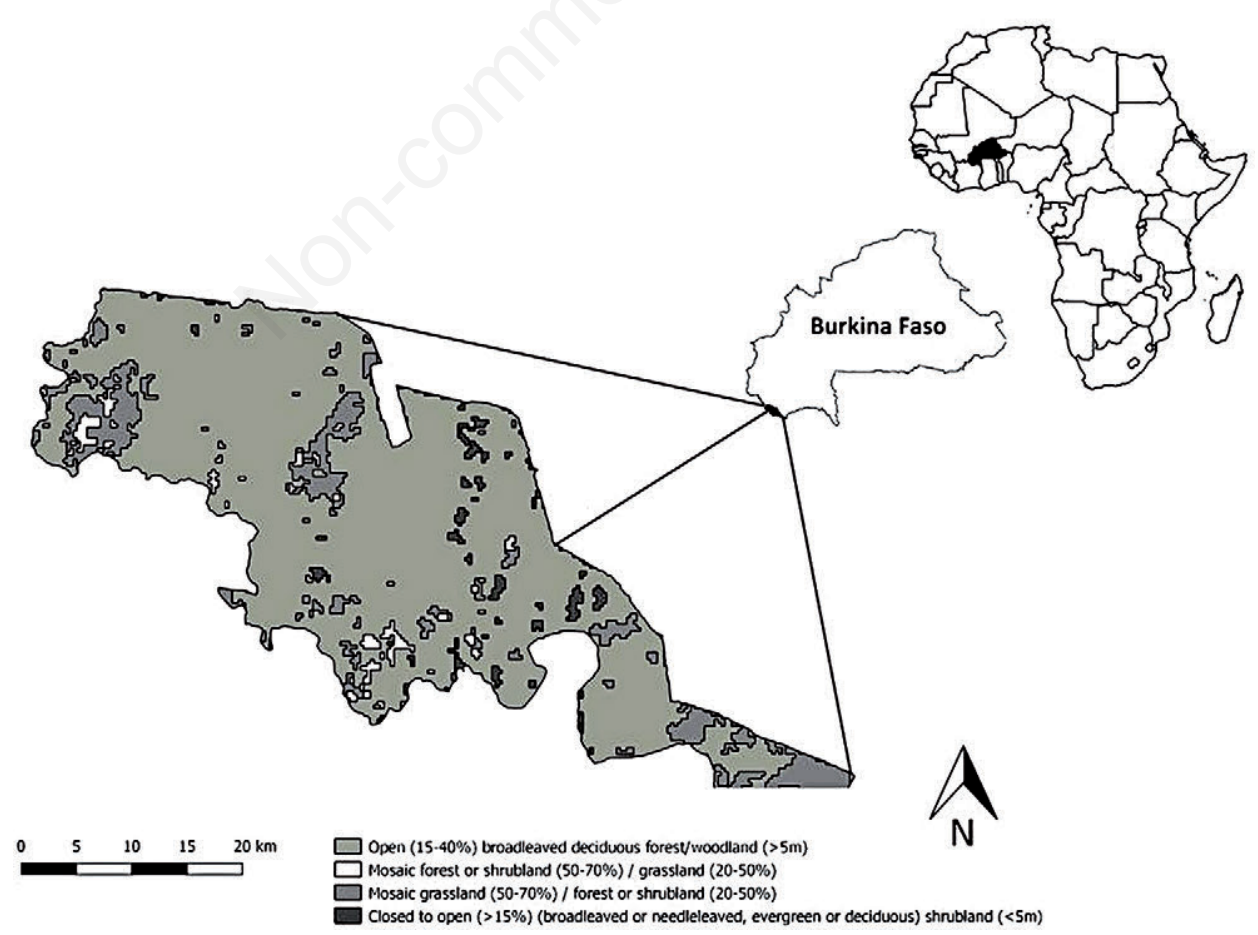

Figure 1. Map of Burkina Faso, showing the Comoé-Leraba National Park. 
Because we could not determine the exact age of individual animals from direct observations, we classified individuals as either juveniles or adults based on morphological characteristics, including the general appearance of the individual, such as body shape and size, as well as the eruption of the tusk (for Phacochoerus africanus) or horns (for horned ungulates). The juvenile category consisted of (i) calves, characterized by their pinked colours and the capacity to walk under the belly of their respective mothers, and (ii) subadults, individuals that were clearly not calves and showed no signs of adulthood. The adult category included fully matured individuals with such characteristics as appropriate height, body size, presence of horns, tusk, etc.

\section{The predictive modeling and the statistical analyses}

We predicted that for species with lower detectability scores, sex ratios and age structures would vary to a greater degree across years than for species with higher detectability because of a much stronger effect of chance. So, assuming an interspecific similar population abundance, we established three independent variables that may make an ungulate species more or less visible during line transects: body size, habitat preferences, and group size. Detectability increases in species (i) with larger body size, (ii) that use open versus densely vegetated habitats, and (iii) that live in large groups compared to small groups or as solitary individuals. Thus, for each ungulate species, we assigned a score ( 1 to 3 ) for each of these three variables, with 1 being assigned to low detectability characteristics (i.e., small body size, densely vegetated habitats, and solitary/small groups), up to 3 for high detectability characteristics (i.e., large body size, open habitats, and large groups). Scores were assigned to each species based on published research (Haltenorth and Diller 1985; Estes 1991). The "overall detectability score" (OOS) for each species was given by the sum of the three species-specific scores relative to the three analyzed variables (Table 1$)$. We empirically determined whether each species had a high OOS $(\geq 6.5)$, a medium OOS (4.1-6.4), or a low OOS (3-4). If a

Table 1. Summary of the "detectability" scores for the various species in relation to their size $(1=$ small, 2 = medium, 3 = big $)$, habitat $(1=$ very dense vegetation, $2=$ bushy-open, $3=$ open $)$, and group size $(1=$ solitary of small groups, $2=$ mid-size groups, $3=$ large groups $)$. Predicted $=$ the "detectability" score that can be predicted on the basis of the three above-mentioned variables; Observed $=$ the observed interannual consistency of sex-ratio and age structure of observed individuals across the study period.

\begin{tabular}{lcccccc} 
& Size & Habitat & Group & Sum & Predicted & Observed \\
Alcelaphus buselaphus Pallas, 1766 & 3 & 3 & 3 & 9 & High & High \\
\hline Syncerus caffer Sparrman, 1779 & 3 & 2 & 3 & 8 & High & Low \\
\hline Cephalophus rufilatus Gray, 1846 & 1 & 1 & 1 & 3 & Low & Low \\
\hline Sylvicapra grimmia Linnaeus, 1758 & 1 & 1.5 & 1 & 3.5 & Low & Low \\
\hline Kobus kob (Erxleben, 1777) & 2 & 1.5 & 2 & 5.5 & Medium & Medium \\
\hline Kobus ellipsiprymnus Ogilby, 1833 & 2 & 2 & 2 & 6 & Medium & Medium \\
\hline Redunca redunca Pallas, 1767 & 1 & 1 & 1 & 3 & Low & Low \\
\hline Hippotragus equinus & 3 & 3 & 3 & 9 & High & High \\
É. Geoffroy Saint-Hilaire, 1803 & 3.5 & 1.5 & 1 & 5 & Medium & Low \\
\hline Tragelaphus scriptus Pallas, 1766 & 2.5 & 1.5 & 1 & 3.5 & Low & Low \\
\hline Ourebia ourebi Zimmermann, 1783 & 1 & 1.5 & 1.5 & 6.5 & High & High \\
\hline Phacochoerus africanus Gmelin, 1788 & 2 & 3 & &
\end{tabular}


species had a high OOS, the interannual inconsistency of its sex ratio and age structure should in theory be lower than in a species with a low OOS. We determined the speciesspecific interannual inconsistency in these demographic parameters by applying some criteria that were unambiguously determined when reporting the year-by-year differences in sex ratio (expressed as \% of males versus females) and size structure (expressed as \% of juveniles versus adults). These criteria were:

(a) high consistency in sex-ratio and age structure: 1) all sex and age groups are present in all years of study; 2$)$ their percent contributions are relatively stable $(<25 \%$ variation $)$ across the years of study;

(b) medium consistency in sex-ratio and age structure: 1) all sex and age groups are present in most years of study, but not in one or two years; 2) their percent contributions show a $26-50 \%$ variation across the years of study;

(c) low consistency in sex-ratio and age structure: 1) at least one sex or age group is not present in at least three years of study; 2) their percent contributions show a $>50 \%$ variation across the years of study.

Observed score for interannual consistency of sex ratio and age structure in each species was correlated with the observed sample size using Spearman's rank correlation coefficient. In this analysis, the independent variable, interannual consistency score, was ranked from 1 to $3(1=$ low, $2=$ medium, and 3 = high). Differences in sex-ratio frequencies, either within species or overall, were assessed by observed-versus-expected $\chi^{2}$ test. All statistical tests were performed by PAST version 3.0 software, with alpha set at $5 \%$.

\section{Results}

We recorded 1,143 individuals belonging to 11 species of both sexes and age structures of each species (unsexed individuals were not included in this count). The raw dataset concerning the study species is given in the supplementary materials (Table S2). Overall, the number of observed males and females did not differ significantly $\left(\chi^{2}=0.59, \mathrm{df}=1, \mathrm{P}=0.559\right)$, and juveniles accounted for $33.3 \%$ of the total observed individuals.

Three species showed a high interannual consistency of the age and sex structures across years: Alcelaphus busephalus, Hippotragus equinus and Phacochoerus africanus (Table 1). In $A$. busephalus, females were more abundant than males in all years of study (but not significanly: $\chi^{2}=2.8, \mathrm{df}=5, \mathrm{P}=0.731$ ), and juveniles were always observed; however, in 2010, there was a considerably higher frequency of encounters with juveniles than in the following years (Figure 2). In H. equinus, there were similar patterns as the above-mentioned species, with the sex ratio being equal in each year of study $\left(\chi^{2}=8.3, \mathrm{df}=5, \mathrm{P}=0.136\right)$ and with a considerably higher frequency of encounters with juveniles in the year 2010 than in the following years (Figure 2). In P. africanus, the sex ratio was also equal and stable across years $\left(\chi^{2}=8.16, \mathrm{df}=5, \mathrm{P}=0.151\right)$, and the percentage of juveniles was stable in the population (Figure 2).

Two species (Kobus kob and Kobus ellipsiprymnus) showed a medium interannual inconsistency of the age and sex structures across years. In $K$. $k o b$, sex ratio was even throughout the study period $\left(\chi^{2}=2.28, \mathrm{df}=5, \mathrm{P}=0.843\right)$, and juveniles constantly accounted for less than $20 \%$ of the observed individuals each year. In 2018 , no juvenile was observed during the line transect surveys (Figure 2). In K. ellipsiprymnus, the sex ratio was significantly skewed toward females $\left(\chi^{2}=11.05, \mathrm{df}=5, \mathrm{P}<0.05\right)$, and juveniles, which were observed in each year of study, accounted for a substantial percentage of the recorded 
individuals, with a peak in 2012 when juveniles comprised more than $80 \%$ of the observed individuals (Figure 2).

In the remaining six species, the interannual consistency of the age and sex structures across years was low. In Tragelaphus scriptus, the sex ratio was even across the years $\left(\chi^{2}=6.05, \mathrm{df}=5, \mathrm{P}=0.300\right)$, but juveniles were seldom observed (Figure 2). In Ourebia ourebi, there was no stability across years, with juveniles being observed only in three years, and males varying from less than $40 \%$ to $100 \%$ of the observed individuals (in 2018 , but with just n=1) (Figure 2). In Syncerus caffer, juveniles accounted for a great percentage of the recorded individuals in three years (2010, 2012, and 2018), but a very low percentage in 2011, also with no stability in sex ratio being identified (Figure 2). In Cephalophus rufulatus and Redunca redunca, we did not observe even a single juvenile throughout the study period, and the sex ratio varied from $100 \%$ males to a predominance of females, and a similarly high interannual inconsistency in sex ratio and proportion of juveniles in the sample was also recorded in Sylvicapra grimmia (Figure 2).

In nine of 11 species $(82 \%)$, the predicted OOS matched the observed score (Table 1). The two exceptions were T. scriptus (with a predicted medium OOS and an observed low score for stability of sex ratio and age structure) and, especially, S. caffer, which was predicted to have a high OOS but resulted in a low observed score (Table 1). In these two species, the frequencies of the various group sizes at each sighting along the line transects were significantly different $\left(\chi^{2}=41.1, \mathrm{df}=3, \mathrm{P}<0.0001\right)$, with all T. scriptus sightings being single individuals or

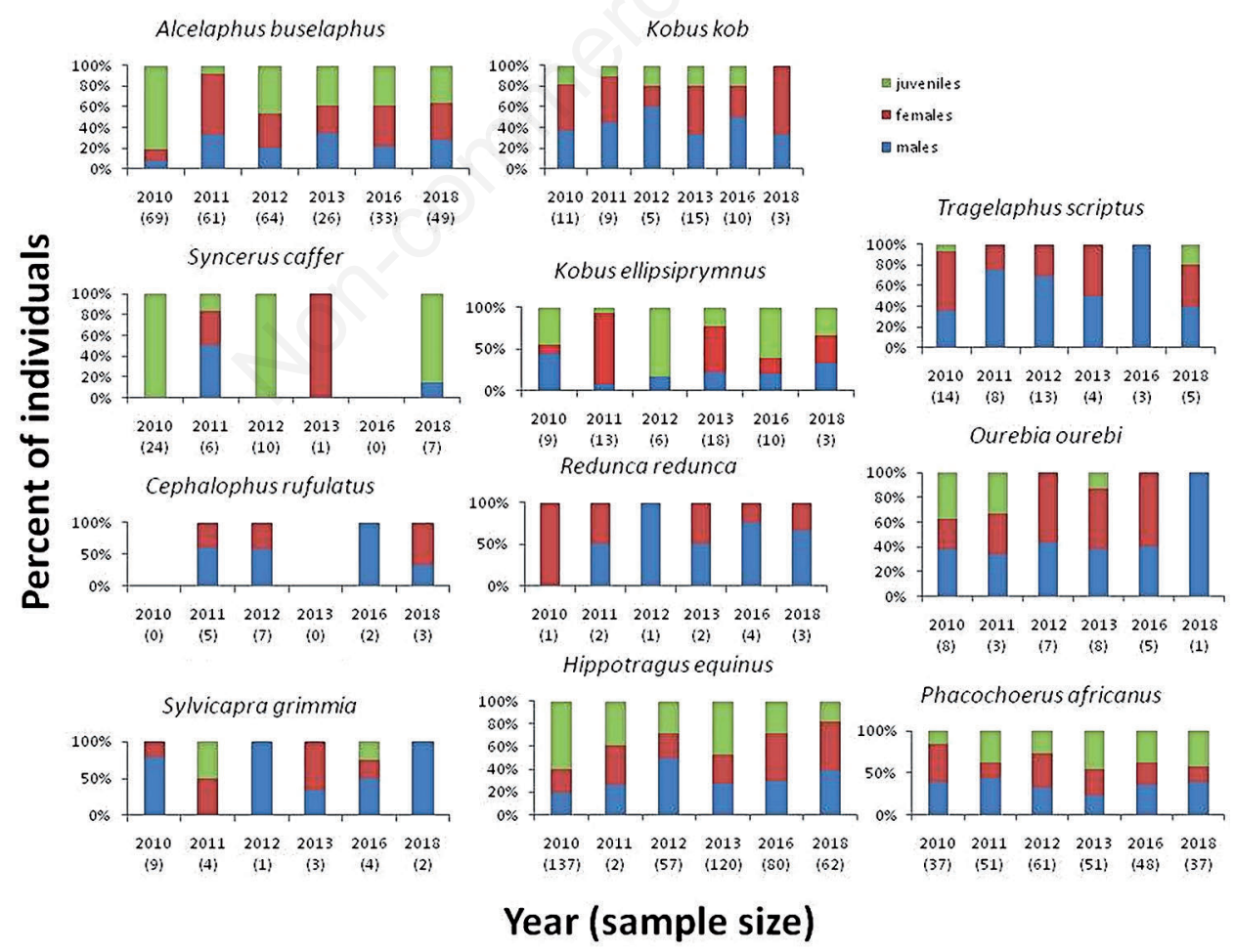

Figure 2. Percentages of males, females and juveniles, for each of the 11 ungulate species at the Comoé-Leraba National Park, by year. 
very small groups, whereas those of $S$. caffer being either single individuals/small groups of relatively large groups, with no intermediate values at all (Figure 3).

The observed score for stability of sex ratio and age structure was significantly influenced by the observed sample size throughout the whole period $\left(r_{s}=0.90, n=11\right.$, $\mathrm{P}<0.001$ ), thus showing that the most elusive species are those with the highest variation in their observed demographic parameters.

\section{Discussion}

Our study showed that sex ratios and age structures of West African ungulates varied greatly by species and by year, and that the instability of these demographic parameters across years can be effectively predicted by considering just three independent speciesspecific variables (body size, habitat type, and group size). In fact, we accurately predicted the level of inconsistency of these demographic parameters in nine of eleven species, with only one species ( $S$. caffer) clearly contradicting our predictions. In the case of $S$. caffer, we think that the remarkable inconsistency in its group sizes at the study area, even within single years (compared to available literature showing that this species lives in large groups; Halternorth and Diller 1985; Estes 1991), had affected the precision of our prediction.

Our study gave remarkable indications for future studies in West African savannahs, when direct sightings along line transects are used for data collection. It is clear that not all the species in a given ungulate assemblage can be detected with the same probability, thus some species are more suitable for line-transect surveys directed at studying their demographic attributes (for instance $A$. busephalus and $H$. equinus) and other species that are very unsuitable for line transects (for instance, $R$. redunca and $C$. rufulatus). Thus, we recommend alternative methods to study population demography attributes for the species that showed high inconsistency in sex ratio and percent of juveniles during the present study. Camera traps may represent an important tool for studying these species in addition to just line transects. However, any method shows point of strength and point of weakness,

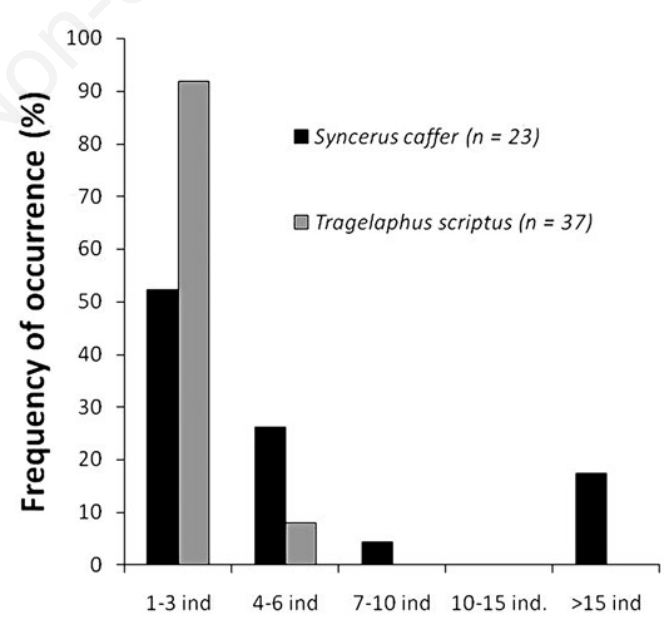

Group size at each sighting

Figure 3. Observed group size at each sighting of Syncerus caffer and Tragelaphus scriptus (expressed as percent frequency of each group-size-interval in the total observed independent sighting events) during line transects at the study area. 
and therefore also camera traps have their weaknesses: reduced sample numerosity is probably the main shortcoming of this latter method. Although it is obvious that total sample size has an effect on the consistency of the examined traits, it should be remarked that some species that were frequently observed during our study (for instance, T. scriptus, S. caffer, and $O$. ourebi) still had a low score of stability of sex ratio and age structure.

Importantly, our study shows that it is easy to predict the score of interannual consistency of sex ratio and age structure of a given species by simply determining a priori "detectability" score for each species by using the existing literature if available, or that relative to a closely related species if literature is not available. Using an "expert-based model approach" as the one presented in this paper, experimenters can understand whether direct sightings of animals along line-transect surveys are appropriate for determining demographic parameters of a species, thus minimizing the risk of getting biased results for the least suitable species by applying a methodology (line transect surveys) that is relatively expensive and time consuming (Hema et al. 2017b). Obviously, among the various demographic parameters, also the simple abundance (and density) along the transect could be affected in species having low detectability scores.

\section{Acknowledgements}

Fieldwork was financed by the PAPSA (Projet d'Appui à la Productivité agricole et à la Sécurité Alimentaire). Thanks to the Minister in charge of wildlife and forests of Burkina Faso for extending support towards these studies, and to two anonymous reviewers for their comments on the submitted draft. In particular, we thank Urbain Belemsobgo for his substantial contributions to the study. We are mostly grateful to the communities of the villages of Folonzo and Massadeyirikoro for their contribution to the smooth running of the field operations.

\section{Conflict of interest}

None.

\section{Contributions}

LL and EMH produced the idea; EMH defined the protocol; EMH, YO, MAIT and MK collected the data; LL and GA analysed the data; GA, LL and EMH drafted the manuscript; all authors revised and approved the various drafts.

\section{References}

Amici V, Battisti C. 2009. Selecting focal species in ecological network planning following an expertbased approach: a case study and a conceptual framework. Landscape Research. 34:545-561.

Battisti C, Dodaro G, Franco D. 2014. The data reliability in ecological research: a proposal for a quick self-assessment tool. Natural History Science. 1:75-79.

Battisti C, Luiselli L. 2011. Selecting focal species in ecological network planning following an expertbased approach: Italian reptiles as a case study. Journal for Nature Conservation. 19:126-130.

Berger J, Gompper ME. 1999. Sex ratios in extant ungulates: products of contemporary predation or past life histories? Journal of Mammalogy. 80:1084-1113.

Bourlière F. 1965. Densities and biomasses of some ungulate populations in eastern Congo and Rwanda, with notes on population structure and lion/ungulate ratios. African Zoology. 1(1):199-207.

Caughley G. 1977. Analysis of Vertebrate populations. London: Wiley. 234 pp. 
Clutton-Brock TH, Coulson T. 2002. Comparative ungulate dynamics: the devil is in the detail. Philosophical Transactions of the Royal Society of London. Series B: Biological Sciences. 357(1425):1285-1298.

Dasmann RF, Mossman AS. 1962a. Abundance and population structure of wild ungulates in some areas of Southern Rhodesia. Journal of Wildlife Management. 26:262-268.

Dasmann RF, Mossman AS. 1962b. Population studies of impala in southern Rhodesia. Journal of Mammalogy. 43:375-395.

DeCesare NJ, Hebblewhite M, Bradley M, Smith KG, Hervieux D, Neufeld L. 2012. Estimating ungulate recruitment and growth rates using age ratios. Journal of Wildlife Management. 76:144-153.

Festa-Bianchet M., Gaillard JM, Côté SD. 2003. Variable age structure and apparent density dependence in survival of adult ungulates. Journal of Animal Ecology. 72:640-649.

Gaillard JM, Duncan P, van Wieren SE, Loison A, Klein F, Maillard D. 2008. Managing large herbivores in theory and practice: is the game the same for browsing and grazing species? In: Gordon IJ, Prins HHT, editors. The Ecology of Browsing and Grazing. Berlin and Heidelberg: Springer-Verlag. Pp. 293-307.

Ginsberg JR, Milner-Gulland EJ. 1994. Sex-biased harvesting and population dynamics in ungulates: implications for conservation and sustainable use. Conservation Biology. 8:157-166.

Guinko S. 1984. Végétation de la Haute-Volta. Thèse d'Etat, Sciences Naturelles. Université de Bordeaux. $318 \mathrm{pp}$.

Estes RD. 1991. The behavior guide to African mammals including hoofed mammals, carnivores, primates. Berkeley: University of California Press. 611 pp.

Haltenorth T, Diller H. 1985. Mammifères d'Afrique et de Madagascar. Paris: Delachaux \& Niestlé. $397 \mathrm{pp}$.

Hema EM, Ouatara Y, Karama M, Petrozzi F, Di Vittorio M, Guenda W, Luiselli L. 2017a. Population dynamics of medium and large mammals in a West African gallery forest area and the potential effects of poaching. Journal of Threatened Taxa. 9:10151-10157.

Hema EM, Di Vittorio M, Barnes RFW, Guenda W, Luiselli L. 2017b. Detection of interannual population trends in seven herbivores from a West African savannah: a comparison between dung counts and direct counts of individuals. African Journal of Ecology. 55:609-617.

Hillman JC. 1986. Aspects of the biology of the bongo antelope Tragelaphus eurycerus Ogilby 1837 in south west Sudan. Biological Conservation. 38:255-272.

Karanth KU, Sunquist ME. 1992. Population structure, density and biomass of large herbivores in the tropical forests of Nagarahole, India. Journal of Tropical Ecology. 8:21-35.

Mason DR. 1990. Monitoring of sex and age ratios in ungulate populations of the Kruger National Park by ground survey. Koedoe. 33:19-28.

Ogutu JO, Bhola N, Piepho HP, Reid R. 2006. Efficiency of strip- and line-transect surveys of African savanna mammals. Journal of Zoology. 269:149-160.

Owen-Smith N, Mason DR. 2005. Comparative changes in adult vs. juvenile survival affecting population trends of African ungulates. Journal of Animal Ecology. 74:762-773.

Plumptre AJ. 2000. Monitoring mammal populations with line transect techniques in African forests. Journal of Applied Ecology. 37:356-368.

Spinage CA. 1972. African ungulate life tables. Ecology. 53:645-652.

Sutherland WJ. 2006. Ecological census techniques: a handbook. Cambridge, UK: Cambridge University Press. XV+432 pp.

Thiombiano A, Kampmann D. 2010. Biodiversity Atlas of West Africa, Volume II: Burkina Faso. Ouagadougou and Frankfurt/Main: GIZ Press. 592 pp.

Turkalo A, Klaus-Hügi C. 1999. Group size and group composition of the Bongo (Tragelaphus eurycerus) at a natural lick in the Dzanga National park, Central African Republic. Mammalia. 63:437-448.

Viquerat SMA, Bobo KS, Müller M, Kiffner C, Waltert M. 2012. Estimating forest duiker (Cephalophinae) density in Korup National Park: a case study on the performance of three line transect methods. African Journal of Wildlife Research. 42:1-11.

This article is distributed under the terms of the Creative Commons Attribution

Noncommercial License (by-nc 4.0) which permits any noncommercial use, distribution,

and reproduction in any medium, provided the original author(s) and source are credited. 